\title{
Psychiatry and the global drugs debate: what every psychiatrist needs to know
}

Owen Bowden-Jones, Julia Sinclair and Anne Lingford-Hughes

\section{Summary}

There are few topics that divide public opinion as sharply as the use of psychoactive substances and it is easy to see why. Substance use is complex and can be examined from numerous perspectives, including legal, health, economic, cultural and ethical. These varying approaches can lead to a range of different conclusions. Here we explore some of the common approaches adopted towards drug policy and suggest a number of principles, which may inform a psychiatrist's own view.

\section{Declaration of interest}

A.L.-H. has received honoraria paid into her institutional funds for speaking and chairing engagements from Lundbeck, Lundbeck
Institute UK, Janssen-Cilag, Pfizer and Servier; received research grants or support from Lundbeck and GSK; consulted for Silence, NET Device Corps and Sanofi-Aventis; and also consulted for, but received no monies from, Britannia Pharmaceuticals, GLG, Opiant, Lightlake and Dobrin. O.B.-J. and J.S. have no conflicts of interest to disclose.

\section{Keywords}

Drugs of dependence disorders; education and training; drug policy; decriminalisation; comorbidity.

\section{Copyright and usage}

(C) The Royal College of Psychiatrists 2019
Owen Bowden-Jones (pictured) is an addiction psychiatrist, at Central North West London NHS Foundation Trust. Julia Sinclair is Professor of Addiction Psychiatry and Chair of the Addiction Faculty of the Royal College of Psychiatrists. Anne Lingford-Hughes is Professor of Addiction Biology and Head of Psychiatry at Imperial College London and an addiction psychiatrist at Central North West London NHS Foundation Trust.

Psychoactive substances in many countries are designated as illegal following an assessment of their harms to the individual and the wider community. Evidence and expertise from health and other disciplines are often used to inform these assessments, but they are often ultimately political decisions with research evidence only one of a number of factors considered in a political process. Advocates of this approach point to the unequivocal message legal prohibition gives concerning the negative effect of a particular substance or group of substances on individuals and communities. Detractors cite examples where the evidence used for these assessments is equivocal and/or inconsistently applied. They also highlight the effect a criminal conviction can have, particularly for a young person, on later-life opportunities and the risk of stigmatising those with substance use disorders (SUDs).

A health perspective offers a generally less contentious framework. Patterns of psychoactive substance use, irrespective of legal status, are described with internationally agreed diagnostic categories such as dependence syndrome. ${ }^{1}$ People who meet diagnostic criteria are considered patients with an illness that is in need of appropriate treatment. Other perspectives include economic, cultural and ethical approaches, all of which are legitimate lenses through which to view the subject, and vary across the world. There is unfortunately not space in this review to consider these in more detail.

The drugs debate is made more complicated by the huge range of substances, each with varying potential for harm, and approaches to prevent and/or manage that harm. Possible therapeutic benefits of some illicit substances, such as ketamine, cannabis and psilocybin, and the effect of their legal status on therapeutic development adds further complexity to the debate, as does comparisons with legal psychoactive substances including alcohol and nicotine.

Globally, governments are grappling with this complexity through drug policies with stated objectives ranging from a drug-free society to fully legal markets. A small number of countries have recently enacted policies that either decriminalise drug use or sanction commercialised legal drug markets with minimal regulation. In the UK, the government's Drug Strategy 2017 takes a broad approach with three key strands, reducing demand, restricting supply and building recovery. The strategy is underpinned by the Misuse of Drugs Act 1971 (MDA). In 2016, the Psychoactive Substance Act brought into force a blanket ban on all psychoactive substances not described in the MDA.

Given the lack of current international consensus, how should psychiatrists think about illicit psychoactive substances? Although psychiatrists will have a range of opinions determined by their personal experiences and values, as doctors specialising in mental health, there are some principles that may be helpful for us to follow. We should perhaps begin by accepting that responding to psychoactive substance use is complex and that it is unlikely that there is a single, simple solution, such as a change in legislation. The drugs debate produces strong opinions, often passionately and persuasively articulated. This makes it especially important that as psychiatrists we carefully scrutinise the available evidence to understand what it really tells us. We should challenge incorrect assumptions and misinformation as well as acknowledging that new evidence may build on or change our own view.

Of key importance to us should be the effect of any approach on people with existing mental health problems. The Royal College of Psychiatrists is one of a small group of organisations with an authoritative voice in advocating for those living with mental health problems. Understanding the potential effect of existing or proposed drug policies on those most vulnerable should be a priority. Perhaps even more important is the possible effect of policies on those vulnerable to developing future mental health problems, particularly young people. Emerging research is steadily clarifying the potential risks, particularly of the longer-term consequences of adolescent substance use. As psychiatrists, we have a responsibility to make sense of this emerging evidence and explain to policy makers, people who use substances and the public what it indicates.

We are living in a period of unprecedented global drug policy experimentation. A great deal of evidence will soon emerge of the intended and unintended consequences of different approaches. This developing evidence is likely to be highly influential in informing the debate. It may be premature, particularly given the relative 
lack of quality evidence, to finalise a position until this evidence is available to us.

As clinicians, when we meet someone experiencing problematic substance use (whether legal or illicit), we understand that the problem involves many different aspects of that person's life. Our training helps us understand complex mental health problems by considering biological, psychological and social dimensions, and this is particularly pertinent for SUDs. We are fortunate that despite the reputation of SUDs as difficult to treat, treatment is actually strongly clinically evidenced, ${ }^{2,3}$ supported by National Institute of Health and Clinical Excellence ${ }^{4}$ and shown to be highly costeffective. $^{5}$

Given the evidence for effectiveness, the recent disinvestment of addiction treatment services is cause for great concern. Addiction treatment budgets in England have been cut by $£ 162 \mathrm{~m} \mathrm{(18 \% )}$ since 2013-2014, reducing the availability and quality of treatment. Addiction services are now commissioned outside mainstream National Health Service structures by local authorities. This further erodes the important collaborations needed between addiction treatment, mental health and acute medical care, to optimise outcomes and assist patients with complex needs to navigate increasingly fragmented systems. This disinvestment also has an effect on training, with fewer trainees being able to gain any experience in addiction psychiatry. The number of available training posts has decreased by over $60 \%$ since 2006 , leaving a generation gap in addiction expertise. Some level of expertise in managing substance-related harm is needed by most psychiatrists and this substantial loss of training opportunity will have an effect far beyond addiction psychiatry itself

While the global policy debate continues, the responsibility for ensuring that appropriately resourced addiction treatment services are available to those who need them falls to local commissioners and national policy makers. As psychiatrists, our role is to advocate for people with SUDs by understanding and articulating what the evidence tell us, supporting clinically proven, cost-effective services and protecting the clinical expertise needed to deliver them.

Owen Bowden-Jones (DD, MB, ChB, FRCPsych, MSC, Addiction Psychiatrist, Central North West London NHS Foundation Trust, UK; Julia Sinclair (D) MB, BS, MRCPsych, DPhil, Professor of Addiction Psychiatry and Chair of the Addiction Faculty, Royal College of Psychiatrists, UK; Anne Lingford-Hughes, MA, PhD, BMBCh, FRCPsych, Professor of Addiction Biology, Head of Psychiatry, Imperial College London; and Addiction

Psychiatrist, Central North West London NHS Foundation Trust, UK

Correspondence: Owen Bowden-Jones, Central North West London NHS Foundation Trust, NWL Club Drug Clinic, 69 Warwick Road, Earl's Court, London SW5 9HB, UK. Email: owen.bowdenjones@nhs.net

First received 26 Mar 2019, final revision 7 Aug 2019, accepted 23 Aug 2019

\section{References}

1 World Health Organization (WHO). International Statistical Classification of Diseases and Related Health Problems (11th Revision). WHO, 2018 (https://icd. who.int/en/).

2 Clinical Guidelines on Drug Misuse and Dependence Update 2017 Independent Expert Working Group. Drug Misuse and Dependence: UK Guidelines on Clinical Management. Department of Health, 2017 (https://assets.publishing. service.gov.uk/government/uploads/system/uploads/attachment_data/file/ 673978/clinical_guidelines_2017.pdf).

3 Lingford-Hughes A, Welch S, Peters L, Nutt D, on behalf of expert group. Evidence-based guidelines for the pharmacological management of substance misuse, addiction and comorbidity: recommendations from BAP. J Psychopharmacology 2012; 26(7): 899-952.

4 National Institute for Health and Care Excellence (NICE). Methadone and Buprenorphine for the Management of Opioid Dependence. NICE (TA114), January 2007 (https://www.nice.org.uk/guidance/ta114).

5 Burkinshaw P, Knight J, Anders P, Eastwood B, Musto V, White M, et al. An Evidence Review of the Outcome That Can be Expected of Drug Misuse Treatment in England. Public Health England, 2017 (https://assets.publishing. service.gov.uk/government/uploads/system/uploads/attachment_data/file/ 586111/PHE_Evidence_review_of_drug_treatment_outcomes.pdf). 